\title{
A novel method for measuring mechanical properties of vascular bundles in moso bamboo
}

\author{
Lili Shang ${ }^{1} \cdot$ Zhengjun Sun $^{1} \cdot$ Xing'e Liu $^{1} \cdot$ Zehui Jiang $^{1}$
}

Received: 18 March 2015/Accepted: 3 July 2015/Published online: 27 October 2015

(c) The Author(s) 2015. This article is published with open access at Springerlink.com

\begin{abstract}
Bamboo is a composite material reinforced axially by fibers called vascular bundles. In this paper, the mechanical stripping method was used to isolate vascular bundles from moso bamboo (Phyllostachys edulis), China's most important commercial bamboo species. The paper focuses on analyzing the suitability of this method for measuring the mechanical properties of single vascular bundles with respect to their location within a bamboo culm. Using a confocal laser scanning microscope (CLSM) and video extensometry testing technique, we found that the tensile mechanical properties of vascular bundle can be determined with great accuracy. The method relies on mechanical stripping to prepare samples at a length scale from individual bamboo, which traditionally increases the difficulty of conducting tests. Therefore, to determine the elastic modulus of vascular bundle material, video extensometry was used for efficient strain detection in tensile experiments. This type of sample preparation minimizes the usual problems encountered when mounting samples. The cross-sectional area of the vascular bundle was determined by CLSM measurement using an ultramicrotome as a cutting tool. Applying this method, the elastic modulus and tensile strength of the vascular bundle of moso bamboo were measured to be $\sim 44.67 \mathrm{GPa}$ and $\sim 709.96 \mathrm{MPa}$, respectively. It is noteworthy that the tensile mechanical properties of the fibrous sheath areas are higher than those observed over the whole area.
\end{abstract}

\section{Zehui Jiang}

jiangzehui@icbr.ac.cn

1 Department of Biomaterials, International Center for Bamboo and Rattan, No. 8, Futong Eastern Avenue, Wangjing Area, Chaoyang District, 100102 Beijing, China
Keywords Vascular bundles - Confocal laser scanning microscope $\cdot$ Video extensometry $\cdot$ Tensile strength

\section{Introduction}

Bamboos have a hierarchical gradient structure, that is, a macroscopic gradient structure in culm diameter and a microscopic one in the bundle sheath distribution [1-4]. A bamboo culm is made up of two kinds of cells, matrix tissue cells (parenchymatous) and sclerenchyma cells (vascular bundle) [5, 6]. Vascular bundles made up of sclerenchyma cells act as reinforcement in bamboo. The mechanical properties of single vascular bundles are of interest to researchers because they determine the mechanical performance of hierarchically structured bamboo and bamboo-based composites [7-9]. Many applications related to the properties of vascular bundles are reported, but the correlation of structure with mechanical properties at the scale of an individual vascular bundle is not yet fully understood. Bamboo scrimber, which is reconstituted the bamboo beam, is typical representative of them, and its performance is better than bamboo because of the homogeneous distribution of vascular bundles; it is used in decoration, furniture, architecture and pack [10, 11]. Original bamboo fiber and bamboo composite pressure pipes are another form of unitization that both mainly use the flexibility of the vascular bundles [12]. Therefore, the study of vascular bundles of bamboo is a reasonable approach for improving the utilization of bamboo according to its properties.

Mechanical properties related to fiber bundles of bamboo have previously been measured $[2,13]$. Amada et al. [14] found a tensile strength of $0.61 \mathrm{GPa}$ and a tensile modulus of $46 \mathrm{GPa}$ for bamboo fiber bundles, which were 
indirectly calculated based on the volume ratio of fibers to parenchymal cells and the macroscopic tensile modulus and strength of bamboo. Yang et al. [15] reported a tensile strength and tensile modulus of $547.68 \mathrm{MPa}$ and $27.60 \mathrm{GPa}$, respectively, at twelve replicates for moso bamboo fiber bundles, using the same calculation method.

On the other hand, few studies have experimentally analyzed the mechanical properties of bamboo vascular bundles. Among existing literature, Ye [16] reported the tensile strength of moso bamboo vascular bundles to be $950 \mathrm{MPa}$ by picking 60 specimens using a blade, while the paper gave no tensile modulus value. Recently, Shao et al. [17] found the tensile strength and modulus of 71 specimens of fiber bundles of moso bamboo detaching and pulling them out from ground tissues at an angle of $10^{\circ}$ to be $482.2 \pm 108.32 \mathrm{MPa}$ and $33.9 \pm 8.16 \mathrm{GPa}$, respectively, while the cross-area of fiber bundle was measured under a microscope equipped with an image analysis system. Furthermore, $\mathrm{Li}$ et al. [18] have also shown that it is possible to extract vascular bundles of a moso bamboo using a $10 \mathrm{wt} \%$ alkali treatment method which resulted in significant change in cross-sectional shape [19-22], and, in this case, the cross-sectional area of the vascular bundle was measured from an image taken under an optical microscope.

In this paper, we found the tested tensile strength and modulus of bamboo vascular bundles were nearly 1.5 and 1.3 times than the data collected by Shao et al. for moso bamboo vascular bundle, respectively. In previous early mentioned studies, the elastic modulus of vascular bundle has been determined from a tensile test, where in most instances, vascular bundle strain was calculated according to crosshead movement or mathematical calculation. The area of the vascular bundles was measured using an image analysis system or optical microscope. However, both methods having some disadvantages, with the boundary of image analysis systems being often blurred, the surface shape information of optical microscope will be lost.

The aim of the present study is to develop a measurement technology for recording load-elongation curves, which is based on a general method for a precise strain determination for vascular bundle test that uses video extensometry. Another advantage of the method is that the cross-sectional area of the sample can be measured with great precision with the aid of a confocal laser scanning microscope.

\section{Materials and methods}

\section{Sample preparation}

Four-year-old moso bamboo samples were taken from a plantation located in Huangshan city, Anhui Province, China. Straight cylinder internodes were cut at heights of
$1 \mathrm{~m}$ from the bottom of the bamboo culm. Straight strips with a length of $100 \mathrm{~mm}$ and a width of $20 \mathrm{~mm}$ were then cut perpendicular to the radial direction at the thicker end of each culm section (Fig. 1a). Each strip was analyzed to determine the mechanical variation of vascular bundles in the radial direction (Fig. 1b). Subsequently, sample slices were steeped in water for $48 \mathrm{~h}$. Single vascular bundles were then carefully removed from the soft slices by hand under a stereo-microscope with a razor blade (Fig. 1c, d). To prevent bending caused by different shrinkage rates of vascular bundles and surrounding parenchyma throughout the seasoning process, the vascular bundles were kept straight, while the surrounding parenchyma was totally eliminated. Finally, to ensure no tissue had occurred during the manual extraction process, the straight vascular bundles were then carefully examined under a microscope.

\section{Tensile test}

Once the samples were prepared, a tensile test was carried out using a universal mechanical testing machine (Instron Microtester 5848, USA). The test was conducted with a crosshead speed of $1.5 \mathrm{~mm} / \mathrm{min}$ and a load cell capacity of $500 \mathrm{~N}$. The strain gauge length of the vascular bundles (about $50 \mathrm{~mm}$ ) was determined using two black spots on the vascular bundles, as well as via indirect detection with a video extensometry from the machine path (Fig. 2a). As the black spot surrounded the vascular bundle, the video extensometer can capture any slight deformation of the vascular bundle in tension. Four pieces of trapezoidal Poplar veneer with $25 \mathrm{~mm}$ length and $1 \mathrm{~mm}$ thickness were also glued on the ends of the specimen to avoid any specimen slide from the clamps (Fig. 2b). Tensile testing was carried out under an environment of $20^{\circ} \mathrm{C}$ at $45-50 \%$ RH. 75 samples were tested. For the calculations, the areas of every broken vascular bundle were determined with a confocal laser scanning microscope (Meta 510 CLSM, Zeiss).

\section{Area measurement}

The broken vascular bundles of approximately $20 \mathrm{~mm}$ in length were firstly dehydrated using alcohol-Spurr resin solutions of different strengths, ranging from alcohol $50 \%$, alcohol $70 \%$, alcohol $90 \%$, alcohol $100 \%$, alcohol:Spurr resins $=2: 1$, alcohol:Spurr resins $=1: 1$, alcohol:Spurr resins $=1: 2$, and Spurr resins $100 \%$. Secondly, the vascular bundles were embedded vertically in the Spurr resin and cured in a plastic mold. After curing, the cross-section of the samples was cut using an ultramicrotome. The ultramicrotome is equipped with a glass knife to obtain a very smooth and thin slice, which in this study, for indenting purposes, was $1.5 \mu \mathrm{m}$ thick. Thirdly, these slices were immersed in $0.1 \%$ acridine orange solution for $20 \mathrm{~s}$ 
Fig. 1 Schematic diagram of sampling: a cutting strips from bamboo culm; b a cross-section of moso bamboo; c a single vascular bundle; $\mathbf{d}$ the crosssection of vascular bundle

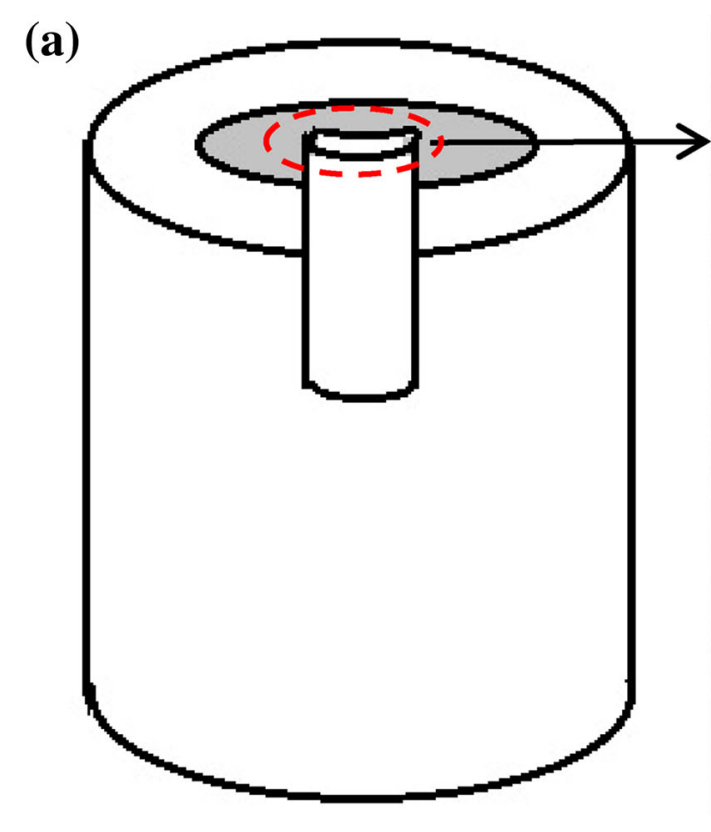

\section{(b)}
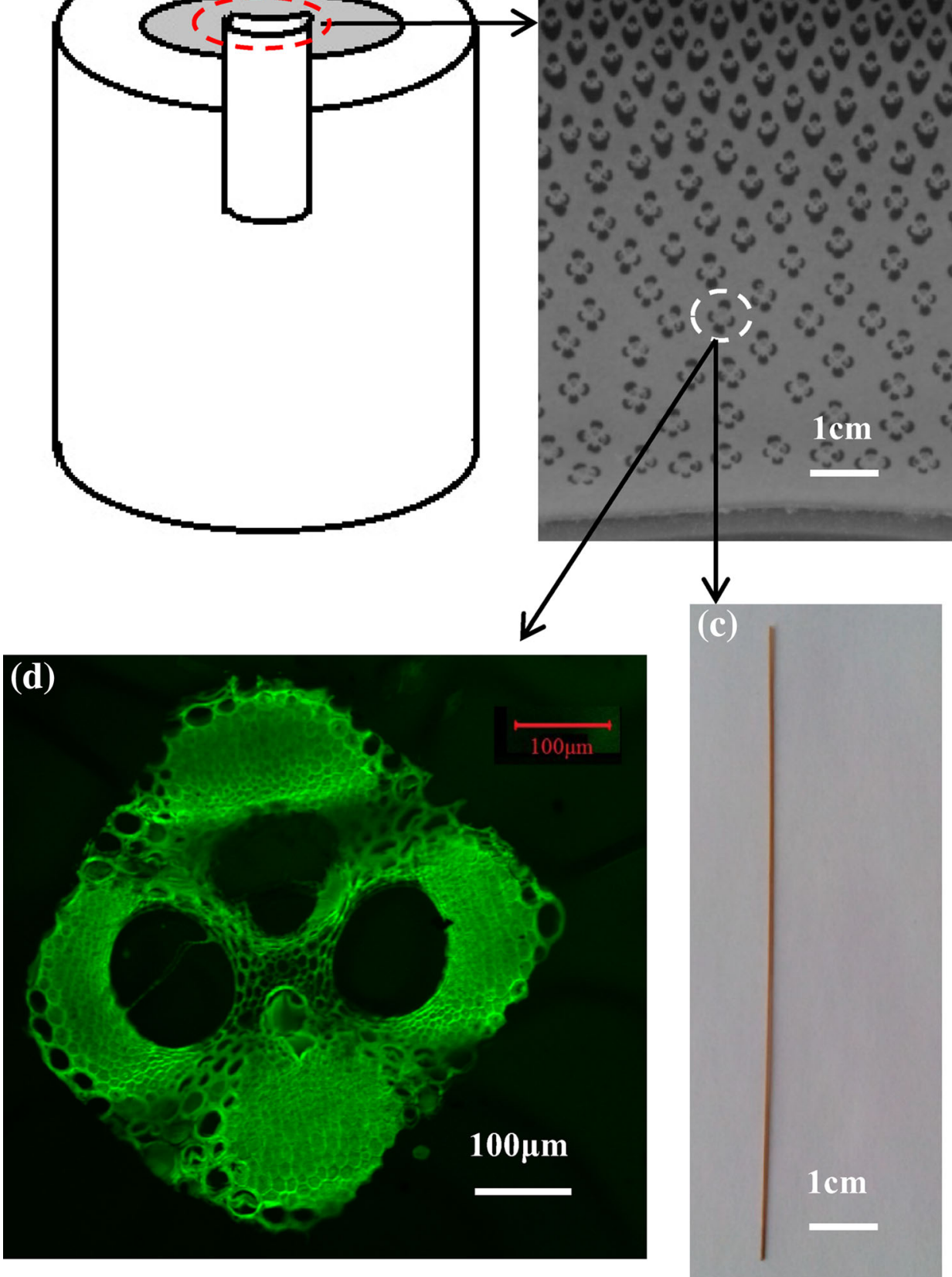

and then rinsed in distilled water several times. Finally, the vascular bundle slices were imaged with a $10 \times$ objective. The area of vascular bundle was then measured with software provided by the instrument producer.

\section{Calculation}

Load-elongation curves were converted to stress-strain curves, with the tensile strength and modulus obtained based on the different area of vascular bundles.

\section{Results and discussion}

The anatomical features of vascular bundles in the moso bamboo

The distribution of vascular bundles in the bamboo crosssection is shown in Fig. 1b. From the image, we could observe that the vascular bundles close to the outer periphery are smaller and denser, while those close to the inner periphery were larger and more sparsely spaced. 
Fig. 2 A single vascular bundle tested in tension a experimental device for the tensile of vascular bundle, $\mathbf{b}$ shape and dimension of vascular bundle used for tensile test

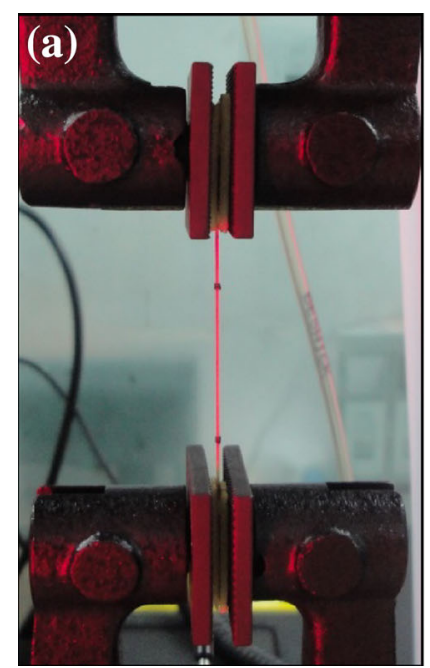

(b)

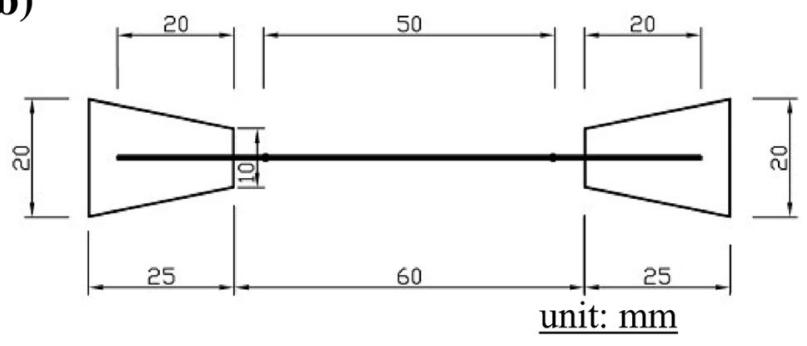

These findings were consistent with the observations of Ray et al. [23]. Earlier work by Ghavami et al. [2] identified this distributions was functionally graded. Vascular bundles arranged in oblique rows and multiple lines. In the cross-section, the morphology and size of the vascular bundles located from the outer to inner sections of the culm also had significant differences. The outer vascular bundles (3/5 of the bamboo wall thickness) showed a dense distribution and smaller in size. They were mainly made of fiber wall accompanied by rudimentary vessel. The morphology of inner vascular bundle was far more stable with a fully developed vessel. There were two different forms of vascular bundles, one was semi-open and others were open. The semi-open vascular bundles were mainly distributed in the outer layer, while the open vascular bundles were found in the inner layer. The outer vascular bundles were often arranged in staggered rows, where they gradually increase in size when moving from locations at the periphery to the middle. By comparison, the inner vascular bundles had a disorderly arrangement yet consistent morphology. The ratio between the radially maximum length and the tangentially maximum width $(R / T)$ of the vascular bundle I was slightly larger near to the outer sections of the culm. From the outer to inner section, the ratio of radially maximum length decreased gradually, while the tangentially maximum width increased. Therefore, the $R / T$ ratio was almost constant near the cavity. In general, the characteristic variations in the vascular bundles depended on the position in the radial direction.

\section{The tensile test for single vascular bundle}

Due to the difficulties using experimental tests, there was very little literature available on how to take direct measurements of the mechanical properties of single vascular bundles. In particular, the precise measurement of a single vascular bundle area was not reported. Yet, this plays an important role in calculating the mechanical strength and Young's modulus. Most researchers currently studied the vascular area of bamboo using ordinary optical microscope to achieve rough measurements [1, 18].

In this paper, a novel method for measuring the area of vascular bundle of bamboo which uses CLSM to give a precise measurement of both the vascular bundle area and its components was now being presented. The main advantage of this new method compared to previous ones was that the accuracy of measurements had been greatly improved due to the clear interface between the fiber sheath and parenchyma in the CLSM.

The shape, including the vessel interior, parenchyma and sieve tubes, was analyzed using the new method in this study. For an easier calculation, the parenchyma and sieve tubes were regarded as a single entity, called the integrated porous. The single vascular bundle could be seen as a combination of the integrated porous and the fibrous sheath. The measuring area of a single vascular bundle included the whole area of the vascular bundle $\left(A_{\mathrm{v}}\right)$, the area of the integrated porous $\left(A_{\mathrm{p}}\right)$ and the area of the fibrous sheath $\left(A_{\mathrm{f}}\right)$. The typical measurements of vascular area are shown in Fig. 3.

The typical stress-strain curves derived from tensile tests on the vascular bundles are shown in Fig. 4 and present a linear-elastic behavior for loading. The elastic modulus of the materials was determined using Hooke's law, assuming a uniform cross-section. This assumption was confirmed by area measurements for five different positions along a single vascular bundle (Fig. 5). The length of the vascular bundle was $10 \mathrm{~cm}$, with area measurement every $2 \mathrm{~cm}$. 


\section{(a) inner}
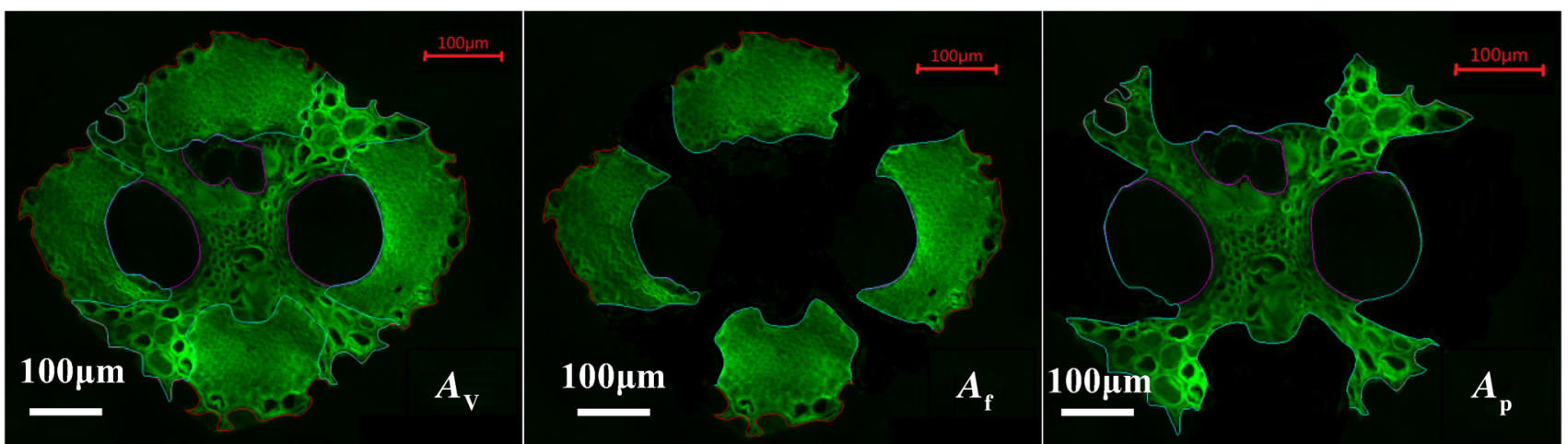

\section{(b) outer}

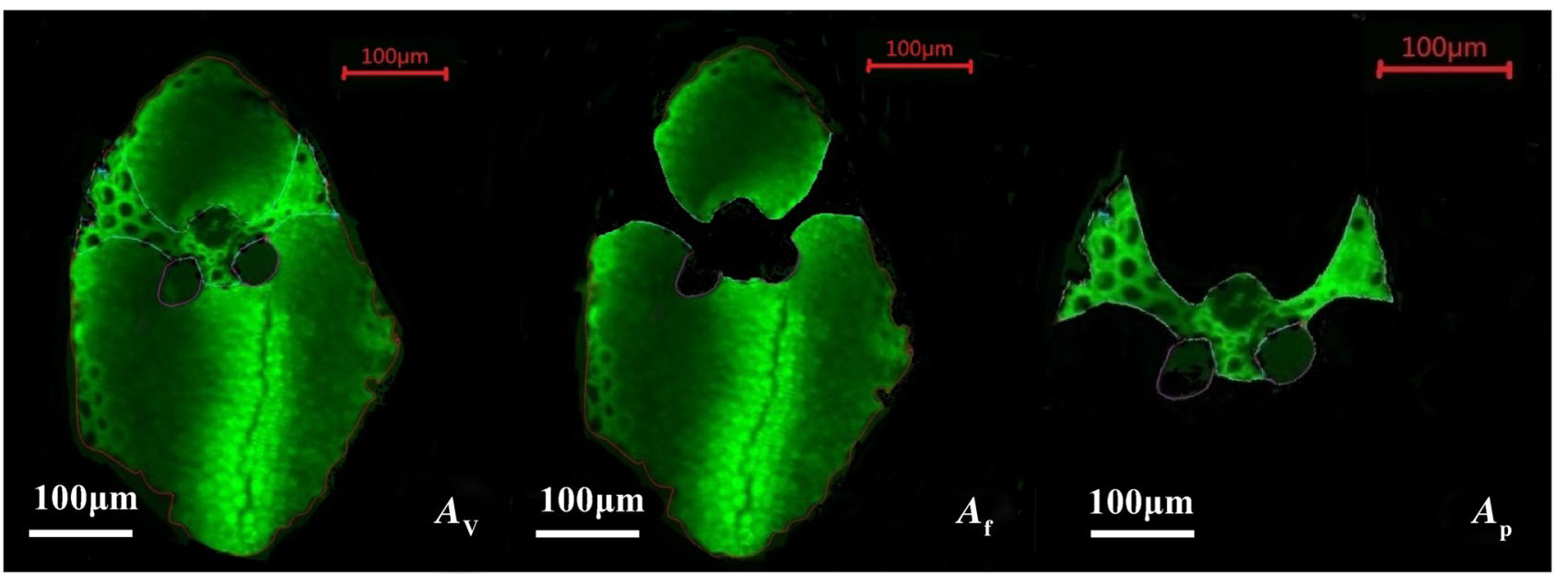

Fig. 3 The typical measuring areas of inner (a) and outer (b) vascular bundles. $A_{\mathrm{v}}$ represents the entity whole area of the vascular bundle, $A_{\mathrm{p}}$ represents the area of the integrated porous, $A_{\mathrm{f}}$ represents the area of the fibrous sheath

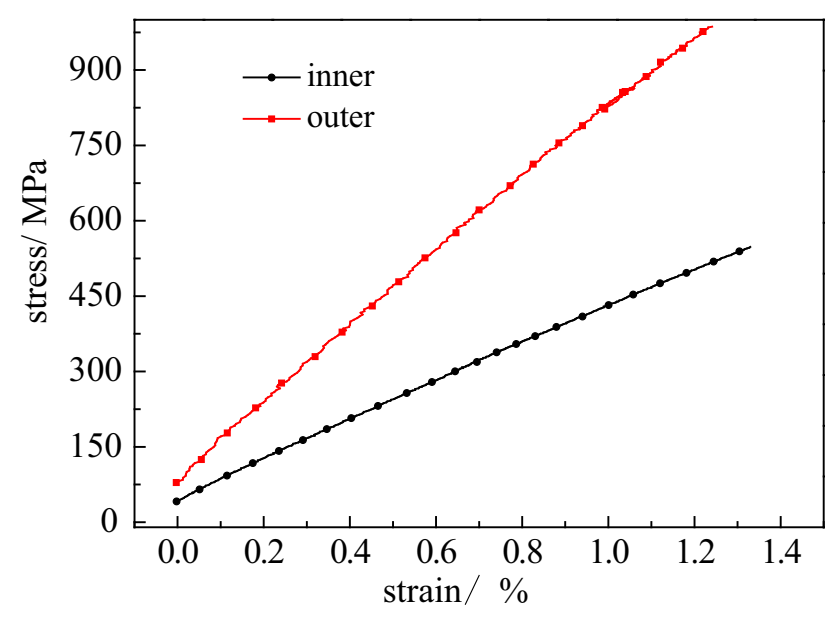

Fig. 4 The stress-strain curve of vascular bundles



Fig. 5 The values of area considered in the calculation of tensile properties of single vascular bundle 
Table 1 Values of average areas, and mechanical properties from tensile test of vascular bundles from moso bamboo

\begin{tabular}{|c|c|c|c|c|c|c|c|c|c|}
\hline \multirow[t]{2}{*}{ Position } & \multicolumn{3}{|c|}{ Vascular bundle entirety } & \multicolumn{3}{|c|}{ Fibrous sheath } & \multicolumn{3}{|c|}{ Integrated porous } \\
\hline & $\begin{array}{l}\text { Area, } \\
\mathrm{mm}^{2}\end{array}$ & $\begin{array}{l}\text { Modulus, } \\
\text { GPa }\end{array}$ & $\begin{array}{l}\text { Strength, } \\
\mathrm{MPa}\end{array}$ & $\begin{array}{l}\text { Area, } \\
\mathrm{mm}^{2}\end{array}$ & $\begin{array}{l}\text { Modulus, } \\
\text { GPa }\end{array}$ & $\begin{array}{l}\text { Strength, } \\
\mathrm{MPa}\end{array}$ & $\begin{array}{l}\text { Area, } \\
\mathrm{mm}^{2}\end{array}$ & $\begin{array}{l}\text { Modulus, } \\
\text { GPa }\end{array}$ & $\begin{array}{l}\text { Strength, } \\
\text { MPa }\end{array}$ \\
\hline Outer & 0.14 & 44.67 & 709.96 & 0.11 & 54.96 & 883.22 & 0.03 & 6.94 & 74.67 \\
\hline Inner & 0.18 & 28.77 & 458.80 & 0.09 & 53.93 & 818.94 & 0.09 & 3.61 & 98.66 \\
\hline
\end{tabular}

\section{The calculation mechanical properties of vascular bundles}

The elastic modulus and tensile strength determined from the loading curves and different areas are shown in Table 1. Taking its cross-section into consideration, the ultimate tensile stress of vascular bundles ranged from 458.80 to $709.96 \mathrm{MPa}$, whereas their modulus of elasticity ranged from 28.77 to $44.67 \mathrm{GPa}$. These values were calculated based on the whole vascular bundle cross-section. These results agreed with the previous findings. Zhang et al. [24] found that tensile modulus of Moso bamboo at locations closer to the outer surface of a culm was more than three to four times larger than comparative values for locations closer to the inner surface. Yu et al. [25] found that tensile strength closer to the outer surface was more than two to three times larger than values reported for samples taken closer to the inner surface.

When calculating the mechanical properties of the fibrous sheath alone, the ultimate tensile stress was found to range from 818.94 to $883.22 \mathrm{MPa}$, while the modulus of elasticity ranged from 53.93 to $54.96 \mathrm{GPa}$. These results were well compared with various earlier investigators. Amada et al. [1] showed that the tensile strength and modulus of fiber sheath were $610 \mathrm{MPa}$ and $46 \mathrm{GPa}$ with the rule of mixture, respectively. Nogata et al. [26] estimated the tensile strength and modulus of pure fiber sheath were $810 \mathrm{MPa}$ and $55 \mathrm{GPa}$, respectively. The tensile properties of the inner vascular bundle and the outer vascular bundle were more or less the same and higher than that determined based on the whole vascular bundle crosssection. Compared to the former, this calculation inferred that different shapes from inner to outer sections had less impact on tensile mechanical properties. If taking considering only the area of integrated porous, the ultimate tensile stress ranged from 74.67 to $98.66 \mathrm{MPa}$, whereas their modulus of elasticity ranged from 3.61 to $6.94 \mathrm{GPa}$. These values were lower than the values calculated using the whole vascular bundle cross-section and fibrous sheath. This variation in tensile mechanical properties was most likely due to the difference in shape of the vascular bundles in the integrated porous in inner and outer sections.
In the above three algorithms, the tensile strength and modulus calculated by the whole area were closest to the actual value considering to the morphology of the vascular bundles. The values of tensile strength also agreed well with those reported by Ye [16] and Li et al. [18], measured on mechanically isolated vascular bundles tested in tension. But the values of elastic modulus were larger than those previously reported. This was most likely due to the fact that the tensile deformation has been directly measured for the first time in this experiment using video extensometry [27].

\section{Conclusions}

The mechanical property of a vascular bundle is closely related to its areas. Using a confocal laser scanning microscope, we were able to measure precisely the area of the vascular bundle. Furthermore, video extensometry can capture small deformation of irregular specimens. The tensile elastic modulus and tensile strength corresponding to the entity area are close to the actual value of the vascular bundle, which are determined to be $\sim 44.67 \mathrm{GPa}$ and $\sim 709.96 \mathrm{MPa}$, respectively. One considerable advantage of testing with our new technique is that it provides a welldefined reference that can be easily and precisely replicated. A further advantage of this method is that samples can maintain their natural properties. And the most notable finding from the study is that the contribution of the fibrous sheath and the integrated porous to the overall mechanical properties is different.

Acknowledgments We would like to thank the 12th Five-Year Key Technology R\&D Program of China (2012BAD23B01) for their financial support of this research. We also thank Mr. Oliver Frith of the International Network for Bamboo and Rattan (INBAR) for his revision of this manuscript.

Open Access This article is distributed under the terms of the Creative Commons Attribution 4.0 International License (http://crea tivecommons.org/licenses/by/4.0/), which permits unrestricted use, distribution, and reproduction in any medium, provided you give appropriate credit to the original author(s) and the source, provide a link to the Creative Commons license, and indicate if changes were made. 


\section{References}

1. Amada S, Munetaka T, Nagase Y (1996) The mechanical structures of bamboos in viewpoint of functionally gradient and composite materials. J Compos Mater 30(7):801-819

2. Ghavami K, Rodrigues CS, Paciornik S (2003) Bamboo: functionally graded composite material. Asian J Civ Eng (Build Hous) 4(1): $1-10$

3. Ray AK, Mondal S, Das SK, Ramachandrarao P (2005) Bambooa functionally graded composite-correlation between microstructure and mechanical strength. J Mater Sci 40(19):5249-5253

4. Tan T, Rahbar N, Allameh SM, Kwofie S, Dissmore D, Ghavami K, Soboyejo WO (2011) Mechanical properties of functionally graded hierarchical bamboo structures. Acta Biomater 7(10):3796-3803

5. Grosser D, Liese (1971) On the anatomy of Asian bamboos, with special reference to their vascular bundles. Wood Sci Technol 5(4):290-312

6. Obataya E, Kitin P, Yamauchi H (2007) Bending characteristics of bamboo (Phyllostachys pubescens) with respect to its fiberfoam composite structure. Wood Sci Technol 41(5):385-400

7. Okubo K, Fujii T, Yamamoto Y (2004) Development of bamboobased polymer composites and their mechanical properties. Composites Part A Appl Sci Manuf 35(3):377-383

8. Abdul Khalil H, Bhat I, Jawaid M, Zaidon A, Hermawan D, Hadi Y (2012) Bamboo fibre reinforced biocomposites: a review. Mater Des 42:353-368

9. Trujillo E, Moesen M, Osorio L, van Vuure AW, Ivens J, Verpoest I (2014) Bamboo fibres for reinforcement in composite materials: strength Weibull analysis. Compos A Appl Sci Manuf $61: 115-125$

10. Nugroho N, Ando N (2000) Development of structural composite products made from bamboo I: fundamental properties of bamboo zephyr board. J Wood Sci 46:68-74

11. Nugroho N, Ando N (2001) Development of structural composite products made from bamboo II: fundamental properties of bamboo zephyr board. J Wood Sci 47:237-242

12. Sun DB, Yang L, Tan L, Yang QB (2011) Basic properties of natural bamboo fiber. Chem Fiber Text Technol 40(3):13-15

13. Yu WJ, Yu YL, Jiang ZH (2006) Properties of bamboo fiber reinforced material. J Northeast For Univ 34(4):3-6
14. Amada S, Ichikawa Y, Munekata T, Nagase Y, Shimizu H (1997) Fiber texture and mechanical graded structure of bamboo. Compos B Eng 28:13-20

15. Yang YF, Liu ZK (1996) Phyllostachys pubescens wood: tensile elastic modulus and tensile strength. J Zhejiang For Collage 13(1):21-27

16. Ye MQ (1995) Evaluation of the tensile strength of bamboo bundle. Quar J For 9(1):29-37

17. Shao ZP, Fang CH, Huang SX, Tian GL (2010) Tensile properties of Moso bamboo (Phyllostachys pubescens) and its components with respect to its fiber-reinforced composite structure. Wood Sci Technol 44(4):655-666

18. Li XB, Shen SP (2011) The mechanical properties of bamboo and vascular bundles. J Mater Res 26(21):2749-2756

19. Zakikhani P, Zahari R, Sultan MTH, Majid DL (2014) Extraction and preparation of bamboo fibre-reinforced composites. Mater Des 63:820-828

20. Amel BA, Paridah MT, Sudin R, Anwar UMK, Hussein AS (2013) Effect of fiber extraction methods on some properties of kenaf bast fiber. Ind Crops Prod 46:117-123

21. Nitta Y, Goda K, Noda J, Lee W-II (2013) Cross-sectional area evaluation and tensile properties of alkali-treated kenaf fibres. Compos Part A 49:132-138

22. Cai M, Takagi H, Nakagaito AN, Katoh M, Ueki T, Waterhouse GIN, Li Y (2015) Influence of alkali treatment on internal microstructure and tensile properties of abaca fibers. Ind Crops Prod 65:27-35

23. Ray AK, Das SK, Mondal S, Ramachandrarao P (2004) Microstructural characterization of bamboo. J Mater Sci 39(3):1055-1060

24. Zhang XD, Cheng XC, Zhu YX (2006) Variation of bending performance with different location of bamboo. J Nanjing For Univ (Nat Sci Ed) 30(6):44-46

25. Yu HQ, Fei BH, Ren HQ, Jiang ZH, Liu XE (2006) Variation in tensile properties and relationship between tensile properties and air-dry density for Moso bamboo. Sci Silvae Sin 42(3):72-76

26. Nogata F, Takahashi H (1995) Intelligent functionally graded material: bamboo. Compos Eng 5(7):743-751

27. Burgert I, Frühmann K, Keckes J, Fratzl P, Stanzl-Tschegg SE (2003) Microtensile testing of wood fibers combined with video extensometry for efficient strain detection. Holzforschung $57: 661-664$ 